\title{
Bax gene therapy for human osteosarcoma using cationic liposomes in vivo
}

\author{
KENYA OKUMURA ${ }^{1}$, MINORU NAKASE ${ }^{2}$, SHINNOSUKE NAKAMURA ${ }^{2}$, \\ TAKAHIKO KAMEI ${ }^{2}$, MADOKA INUI ${ }^{2}$ and TOSHIRO TAGAWA ${ }^{2}$ \\ ${ }^{1}$ Department of Dentistry and Oral Surgery, National Mie Hospital; \\ ${ }^{2}$ Department of Oral and Maxillofacial Surgery, Faculty of Medicine, Mie University, Mie, Japan
}

Received October 30, 2006; Accepted December 4, 2006

\begin{abstract}
The purpose of this study was to evaluate the anti-tumor effect of human osteosarcoma (HOSM-1) tumor xenografts in nude mice via transfer of the Bax gene using cationic liposomes. The HOSM-1 tumors transplanted into nude mice grew to 5-6 mm in diameter. Following growth of the tumor to this size, liposomes with the Bax plasmid were applied locally to the peripheral tumor (day 0 ) and were applied 3 times per week for 2 weeks (6 times in total). The tumor growth inhibitory effect was evaluated by measuring the tumor volume up to day 40 . The expression of Bax was observed by immunohistochemical analysis and apoptosis was detected using the TUNEL assay. Tumor growth increased only slightly during the administration period, and tumor volume on day 50 was $43 \%$ of that in the saline control group. In the tumor margin $48 \mathrm{~h}$ after the completion of administration, Bax immunoreactivity was detected and apoptotic cells were clearly increased. Since these results suggested that Bax gene therapy using cationic liposome induced apoptosis in HOSM-1 tumor in vivo, we anticipate that this therapy will be useful for the treatment of osteosarcoma.
\end{abstract}

\section{Introduction}

Osteosarcoma is one of the malignant tumors that has a poor prognosis. In particular, relapsed or inoperable cases may require the development of new therapeutic approaches. Gene therapy is an innovative treatment for cancer, and is currently being investigated for osteosarcoma (1).

Bcl-2 belongs to a family of proteins that control cell life and death, and may provide an important clue to the development of new treatments for malignant tumors. Bcl-2 and Bcl-xL inhibit cell death, whereas Bax promotes apoptosis. Bax forms a channel with the voltage-dependent anion channel (VDAC)

Correspondence to: Dr K. Okumura, Department of Dentistry and Oral Surgery, National Mie Hospital, 357 Ozato-kubota, Tsu, Mie 514-0125, Japan

E-mail: okuken@clin.medic.mie-u.ac.jp

Key words: Bax, gene therapy, cationic liposome, apoptosis, osteosarcoma and the adenine nucleotide translocator (ANT) in the mitochondrial membrane, and promotes the release of cytochrome $\mathrm{c}$ $(2,3)$. Cytochrome c forms complexes with Apaf-1 and caspase-9, and apoptosis is induced through the activation of caspase-3 $(4,5)$. Thus, Bax gene therapy has been studied for a variety of lung (6), prostate (7), and gastric cancers (8) in vivo. Our in vitro study using osteosarcoma HOSM-1 cells demonstrated good results (9). Therefore, these positive antitumor effects are anticipated to be translated to the in vivo situation.

A variety of vectors can be used for gene transfer. Viral vectors and liposomes are currently used as the primary gene transfer vectors for transfer into tumor cells. Viral vectors exhibit antigenicity and toxicity in addition to their excellent gene transfer efficiency, and several studies of viral vectors developing pathogenically have been reported in clinical practice (10-13). Cationic liposomes comprise a positively charged lipid-bilayer membrane that can be used to transfer genes into cells by forming a complex with negatively charged DNA. Liposomal vectors are characterized by their ready availability, low antigenicity and toxicity, and high margin of safety. The number of clinical trials for gene therapy using cationic liposome has recently increased (see www.wiley. co.uk/genetherapy/clinical/), and cationic liposomes are considered as clinically useful vectors.

In this study, we investigated the anti-tumor effects of Bax gene therapy using cationic liposomes on human osteosarcoma (HOSM-1 tumor) in vivo.

\section{Materials and methods}

Cell line and culture conditions. A human osteosarcoma cell line (HOSM-1) derived from the mandible was used in this study. This cell line has been well-established in our laboratory (14). Cells were maintained in RPMI-1640 (Invitrogen, Carlsbad, CA) medium supplemented with $10 \%$ fetal bovine serum (FBS; Invitrogen) at $37^{\circ} \mathrm{C}$, under $5 \% \mathrm{CO}_{2}$ in a humidified atmosphere. HOSM-1 cells possess a point mutation in the p53 gene at codon 306, which changes this codon from CGA to TGA (15). This codon 306 mutation reduces the transcriptional activation of $\mathrm{Bax}$ (16).

Animals and tumor model. Female BALB/cAJcl nude mice (4- to 5-week-old, 19-22 g) (Nihon Clea, Osaka, Japan) were 
used and housed at the Institute of Laboratory Animals, Faculty of Medicine, Mie University (Thu, Japan). HOSM-1 cells $\left(1 \times 10^{6}\right.$ cells) were inoculated s.c. into the backs of the nude mice. After the tumor size reached 5-6 $\mathrm{mm}$ in diameter, treatment (see below) of the animals was initiated (day 0 ).

Plasmids. The Bax expression plasmid, Bax cDNA in pUSEamp, containing wild-type Bax cDNA under the control of a cytomegalovirus (CMV) promoter, was purchased from Upstate Biotechnology (NY, USA). The plasmid pUSEamp was used as an empty plasmid; i.e., without the Bax gene.

Preparation of liposome-DNA complex. Dioleoyl trimethylammonium propane (DOTAP; Avanti Polar Lipid, Alabaster, AL) and dioleoyl phosphatidyl-ethanolamine (DOPE; Avanti Polar Lipid) were mixed in a 1:1 molar ratio. The lipid film was prepared using a rotary evaporator. After the addition of distilled water, the liposomes were vortexed vigorously for $2 \mathrm{~min}$. Subsequently, $5 \mu 1$ of liposomes $(10 \mathrm{mM})$ was added to $95 \mu \mathrm{l}$ of saline containing $10 \mu \mathrm{g}$ of plasmid DNA and incubated for $15 \mathrm{~min}$ at room temperature.

Western blotting. To observe the time of the Bax protein expression, Western blot analysis was performed using the cells 6-72 h after transfection. Actin was simultaneously immunodetected, to confirm loading of similar amounts of cell lysates. Western blotting was analyzed as described previously (9). Briefly, the cells were treated with the liposome-Bax plasmid complex (100 $\mu 1$ of the liposome-Bax plasmid complex was added to RPMI supplemented with $10 \%$ fetal bovine serum) for $5 \mathrm{~h}$. Six, 12, 24, 48 and $72 \mathrm{~h}$ after completion of transfection, the cells were lysed at $4^{\circ} \mathrm{C}$ for $30 \mathrm{~min}$ in a lysis buffer $(100 \mathrm{mM} \mathrm{NaCl}, 1 \mathrm{mM}$ phenylmethylsulfonyl fluoride, $1 \%$ Triton $\mathrm{X}-100,0.1 \%$ SDS, $0.5 \%$ sodium deoxycholate, $20 \mu \mathrm{g} / \mathrm{ml}$ aprotinin and $20 \mu \mathrm{g} / \mathrm{ml}$ leupeptin). The protein contents of the cell lysates were adjusted to $5 \mathrm{mg} / \mathrm{ml}$ and the cell lysates were applied to 10-15\% SDS-polyacrylamide gradient gels. The proteins were then electrophoretically transferred to PVDF membranes (Immobilon-PSQ; Millipore, Bedford, MA, USA). Blotted membranes were incubated for $1 \mathrm{~h}$ with anti-Bax monoclonal

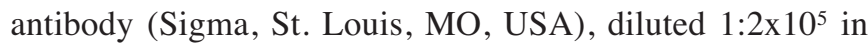
TBS-T; $1 \mathrm{~h}$ with anti-actin monoclonal antibody (Oncogene Research Products, Boston, MA, USA), and then incubated for $1 \mathrm{~h}$ with peroxidase-conjugated secondary antibody. Band detection was performed using an enhanced chemiluminescence system (ECL; Amersham Biosciences, Piscataway, NJ, USA).

Treatment of tumor xenografts in nude mice. The tumor diameter reached 5-6 mm in all mice, 7-9 days after the transfer of HOSM-1 cells. The animals were divided into five groups with four mice per group, and each group was treated with one of the following: 1) saline, 2) liposome alone, 3) Bax plasmid alone, 4) liposome-pUSEamp complex, and 5) liposome-Bax plasmid complex. The liposome-Bax plasmid complex contained $500 \mu \mathrm{M}$ liposome and $10 \mu \mathrm{g}$ Bax plasmid. Each agent $(100 \mu 1)$ was injected along the tumor margin using a 27-gauge needle. The initial day of administration was defined as day 0 . Since the time to overexpression of Bax protein in
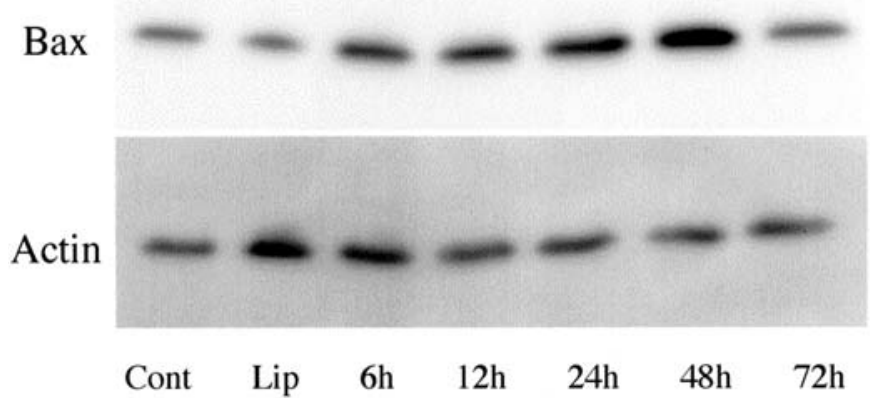

Figure 1. Time-course analysis of Bax expression in HOSM-1 cells, as assessed by Western blotting. The levels of Bax tended to peak at $48 \mathrm{~h}$ and decreased by $72 \mathrm{~h}$.

HOSM-1 cells tends to decrease within $72 \mathrm{~h}$, based on the results of the Western blot analysis (Fig. 1), administration was applied 3 times a week for 2 weeks ( 6 times in total) to maintain the expression of Bax protein in the tumor. Tumors were measured for 40 days from the beginning of administration, and the tumor volume was calculated using the equation $a \times b^{2} \times 0.5$, in which $a$ and $b$ are the largest and smallest diameters, respectively.

Immunohistochemical examination. Tumor tissues were excised $48 \mathrm{~h}$ after transfection, and were fixed in $10 \%$ neutralbuffered formalin. Paraffin-embedded sections (4- $\mu \mathrm{m}$ thick) were deparaffinized in xylene, rehydrated through graded alcohol solutions and were blocked with $10 \%$ dried milk in PBS containing 0.1\% Tween-20 (PBS-T). All further steps were performed using an automated immunohistochemical instrument NexES (Ventana Medical Systems, Tucson, AZ, USA). Slides were pre-treated at $37^{\circ} \mathrm{C}$ with I-View inhibitor for $4 \mathrm{~min}$ and with Protease 1 for $16 \mathrm{~min}$. Slides were incubated sequentially with anti-Bax monoclonal antibody (Sigma), diluted 1:500 in PBS-T for 32 min followed by Blocker A (4 min), Blocker B (4 min), a biotin-conjugated anti-rabbit IgG diluted 1:800 in PBS-T, avidin-D-conjugated horseradish peroxidase (8 $\mathrm{min}$ ), 3,3'-diaminobenzidine tetrahydrochloride (DAB) with $\mathrm{H}_{2} \mathrm{O}_{2}(8 \mathrm{~min})$, copper enhancement as color substrate (4 $\mathrm{min})$, Hematoxylin as a first red counterstain ( $2 \mathrm{~min}$ ), and Bluing Reagent as a post counterstain (2 min). Sections were then dehydrated in graded alcohols.

Terminal deoxynucleotidyl transferase-mediated dUTP nick end-labeling (TUNEL) assay. Apoptosis-related DNA fragmentation was detected by TUNEL, using an Apop-Tag Plus Peroxidase In Situ apoptosis detection kit (Intergen, Oxford, UK). Tumor tissues were excised $48 \mathrm{~h}$ after transfection, and were fixed in $10 \%$ neutral-buffered formalin. Paraffin-embedded sections (4- $\mu \mathrm{m}$ thick) were deparaffinized in xylene and rehydrated through graded alcohols. All further steps were performed using an automated immunohistochemical instrument NexES (Ventana). The slides were pre-treated at $37^{\circ} \mathrm{C}$ with I-View inhibitor for 4 min and with Protease 1 for $16 \mathrm{~min}$. Subsequently they were incubated in working-strength terminal deoxynucleotidyl transferase (TdT) enzyme containing deoxyuridine-5'-triphosphate-digoxigenin 


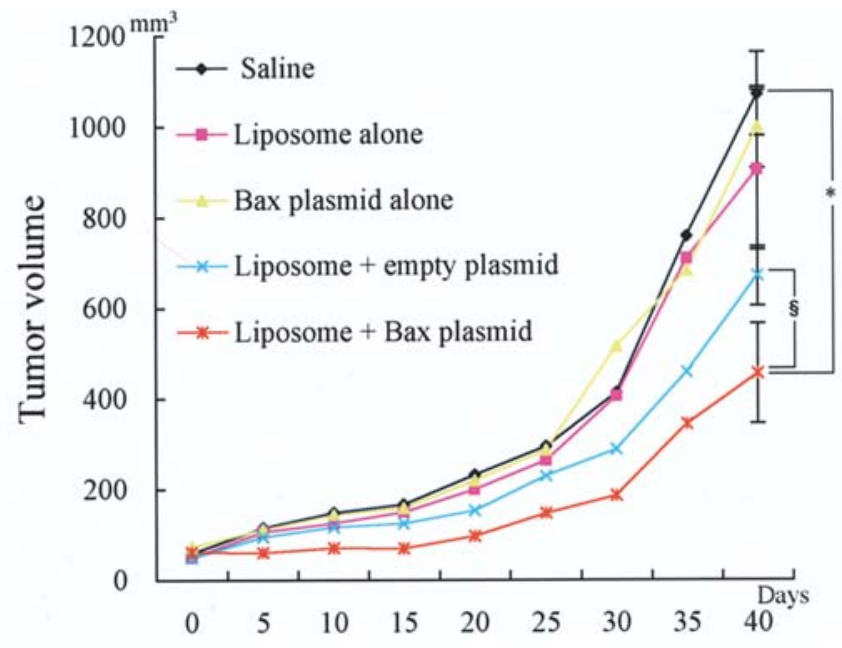

Figure 2. Tumor volume analysis of tumor-bearing mice after injection to peripheral tumor. The growth was inhibited significantly in the Bax gene transfer group at day 11 (at the completion of administration) and at day 40, compared with the other administration groups. ${ }^{*} \mathrm{p}<0.05,{ }^{\S} \mathrm{p}<0.01$, Student's t-test.

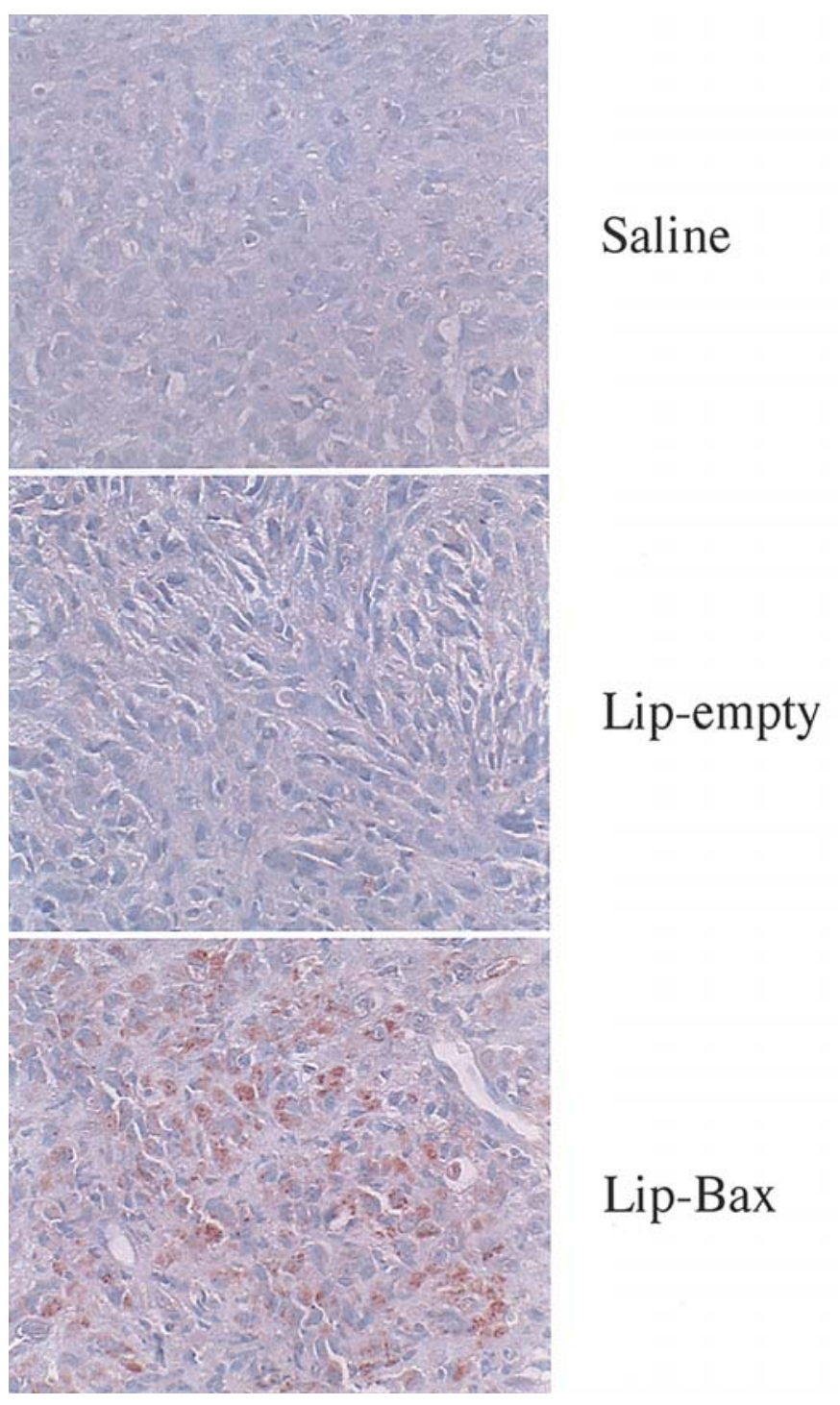

Figure 3. Immunohistochemical analysis for Bax in HOSM-1 tumor $48 \mathrm{~h}$ after completion of administration. Bax immunoreactivity was detected in the limited regions of Bax-transfected tumors. Original magnification x400.

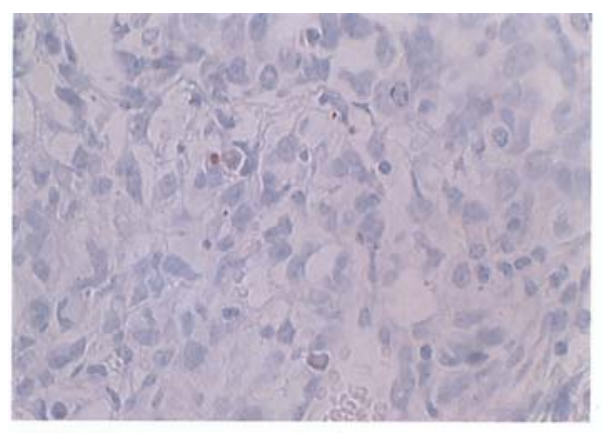

\section{Saline}

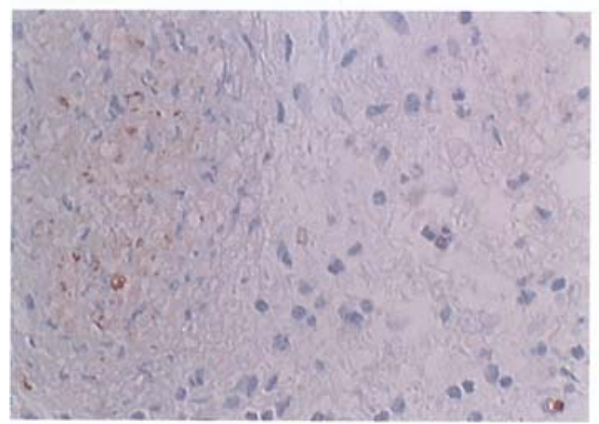

\section{Lip-empty}

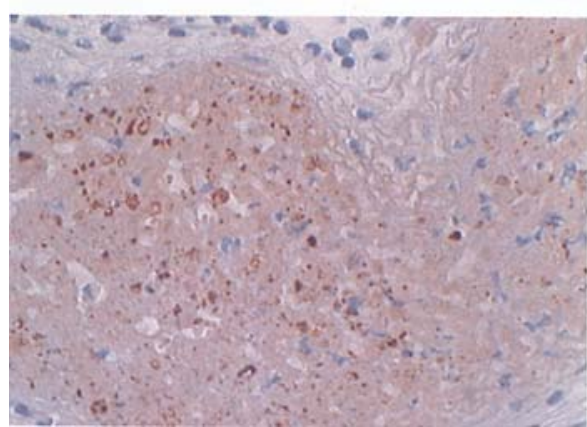

\section{Lip-Bax}

Figure 4. Detection of apoptosis using the TUNEL assay in HOSM-1 tumor $48 \mathrm{~h}$ after completion of administration. Many TUNEL-positive cells were visible in the limited regions of Bax-transfected tumors. Original magnification $\mathrm{x} 400$.

for $32 \mathrm{~min}$. The reaction was terminated with a stop/wash buffer for $30 \mathrm{~min}$. After an anti-digoxigenin antibody fragment carrying a conjugated peroxidase was applied for $32 \mathrm{~min}$, the signals of localized peroxidase enzyme were detected using 3, 3'-diaminobenzidine (DAB) substrate. Hematoxylin and Bluing Reagent were used respectively for $2 \mathrm{~min}$ as the first counterstain and the post counterstain. Sections were then dehydrated in graded alcohols.

\section{Results}

Time-course of Bax expression. The cells were isolated 6-72 $\mathrm{h}$ after transfection and the changes of Bax protein expression were observed over time using Western blot analysis (Fig. 1). Although a band was detected in the control group, enhancement of Bax expression began $6 \mathrm{~h}$ after Bax gene transfer. Subsequently, the expression was gradually enhanced. Bax expression reached maximum at $48 \mathrm{~h}$, but began to reduce $72 \mathrm{~h}$ after the gene transfer.

Tumor growth inhibition following Bax gene transfer in vivo. The average tumor volume ranged from 50 to $70 \mathrm{~mm}^{3}$ at Day 0 in each group. The average tumor volume at the completion 
of administration (Day 11) was $161.2 \mathrm{~mm}^{3}$ in the saline group, and $80.8 \mathrm{~mm}^{3}$ in Bax gene transfer group, which indicated that the growth inhibition effect was $50 \%$ of the saline group. Five days after the completion of administration (Day 16), the tumor increased 3-fold (tumor volume: $174.8 \mathrm{~mm}^{3}$ ) and 1.3-fold (tumor volume: $76.7 \mathrm{~mm}^{3}, 44 \%$ of that of the saline group) in the saline and the Bax-treated groups, respectively. Thereafter, the tumors in the Bax-treated group tended to increase as well, but the average volume at Day 40 was $455.1 \mathrm{~mm}^{3}$ which was $43 \%$ of that of the saline group $\left(1070.2 \mathrm{~mm}^{3}\right)$. The growth inhibition effect was significant, as with the other administration groups (Fig. 2). A similar increase was noted in tumors of the liposome alone group and the Bax plasmid alone group, as well as the saline group, but the liposome-empty plasmid transfer group exhibited only a slight growth inhibitory effect.

Immunohistochemcal analysis for Bax protein. To determine the efficacy of transducing HOSM-1 tumors s.c. implanted into nude mice, we assessed Bax immunoreactivity in HOSM-1 tumors, $24 \mathrm{~h}$ after transfection. Immunohistochemical evaluation revealed detectable Bax immunoreactivity only in the tumor margin, which was the site of local injection in the Bax gene transfer group (Fig. 3). There was no detectable Bax immunoreactivity in the other administration groups, nor in the center of the tumor in the Bax gene transfer group.

Detection of apoptosis. Fig. 4 represents the results of TUNEL staining. Brown-stained TUNEL-positive cells were noted in all administration groups. In the Bax gene transfer group, a significant increase of TUNEL-positive cells as well as immunostaining was evident at the tumor margin. A slight increase of TUNEL-positive cells was noted at the tumor margin in the empty plasmid group, but there were no differences at the center of tumors between the groups.

\section{Discussion}

The Bax gene is downstream of p53 and can promote apoptosis. Bax gene therapy has been investigated for various cancers, and has been shown to have a beneficial inhibitory effect on the growth of lung, prostate, and gastric cancers in vivo. Tunemitu et al (8) reported that $\mathrm{p} 53$ gene therapy had no effect on p53 wild-type gastric cancer (MKN-45 cells) whereas Bax gene therapy did. Our previous studies on the anti-tumor effects of Bax gene therapy on HOSM-1 cells in vitro revealed that Bax gene therapy induced caspase-independent cell death as well as apoptosis. Therefore, the anti-tumor effect may be stronger than the ability to induce apoptosis (9). The result of this study of the effect on HOSM-1 cells in vivo demonstrated the growth inhibitory effect. The involvement of caspase-independent cell death, which was reported in the in vitro studies, remains unconfirmed, but may be influenced by the induction of apoptosis by the increase of Bax proteins in the tumors as indicated by the immunostaining and TUNEL stain findings.

Cationic liposomes may be clinically safe, but their gene transfer efficiency is lower than viral vectors. Viral vectors are widely used in Bax gene therapy investigations. Apoptotic cells $(>50 \%)$ are induced in vitro in prostate (LNCap, PC-3, DU-145, TsuPr(1) cells) $(7,17)$, pancreatic (Panc28 cells)
(18), and lung (A1466 cells) (19) cancer. In in vivo studies, adenoviral vectors have been used in prostate (PC-3 tumors) (7) and gastric (MKN-45 tumors) (8) cancers, and significant growth inhibitory effects have been shown. On the other hand, in vivo studies on Bax gene therapy using liposomes have not been reported in any tumor model. In vitro, apoptosis was induced in 30-40\% of P3L and P3T lung cancer cells (20) and HOSM-1 osteosarcoma cells (9), and was less than that following therapy using viral vectors. However, liposomes have the benefit that they can be used repeatedly due to safety factors. In addition, Almofti et al (21) demonstrated that the transfer efficiency varied with the charge ratio of the liposome/DNA complexes $( \pm)$ and might have a significant effect on the ratio of plasmid DNA to liposome. In this study, a significant growth inhibitory effect was obtained when the administration with the most effective rate in vitro was performed in vivo 3 times per week for 2 weeks. However, the size of the tumor tended to increase gradually during the administration and further improvement of the gene transfer rate might be necessary. It has been reported that gene transfer efficacy would be improved by adding a ligand, such as transferrin, lectin, epidermal growth factor, or insulin, to the cationic liposome (22-24). Bax gene therapy using cationic liposomes will become a more useful gene than therapy with virus vectors if the method of administration is modified. A more efficient anti-tumor effect may be expected if the dosing frequency increases, but adverse reactions induced by Bax gene therapy remain unknown and require further investigation.

Combination therapy with surgical therapy, radiotherapy, or chemotherapy has been conducted as a basic therapy for malignant tumors. The effects of the combination of Bax gene therapy and radiotherapy/chemotherapy have been investigated on some malignant tumors. Enhancement of radiation sensitivity in vivo has been noted in ovarian cancer cells (25) and glioma cells (26). There have been no studies on the in vivo sensitivity of Bax gene therapy to anti-cancer agents, but the in vitro sensitivity to anti-cancer agents by Bax gene transfer increases in breast cancer cells (27), head and neck squamous cell carcinoma cells (28), gastric cancer cells (29), and colon cancer cells (30). Hence, a combination of this therapy with chemotherapy/radiotherapy is expected to be an effective therapy for osteosarcoma.

In conclusion, gene therapy by Bax gene transfer using cationic liposomes is considered to be a useful treatment for osteosarcoma (HOSM-1 tumor), but it will be necessary to improve the method of gene transfer, and study combination therapy with chemotherapy and/or radiotherapy as well as the adverse reactions which could be induced by this therapy.

\section{References}

1. Benjamin R, Helman L, Meyers P, et al: A phase I/II dose escalation and activity study of intravenous injection of OcaP1 for subjects with refractory osteosarcoma metastatic to lung. Hum Gene Ther 12: 1591-1593, 2001.

2. Zou H, Henzel WJ, Liu X, Lutschg A and Wang X: Apaf-1, a human protein homologous to $\mathrm{C}$. elegans CED-4, participates in cytochrome $c$-dependent activation of caspase-3. Cell 90: 405-413, 1997

3. Marzo I, Brenner C, Zamzami N, et al: Bax and adenine nucleotide translocator cooperate in the mitochondrial control of apoptosis. Science 281: 2027-2031, 1998. 
4. Shimizu S, Narita M and Tsuzimoto Y: Bcl-2 family proteins regulate the release of apoptogenic cytochrome $\mathrm{c}$ by the mitochondrial channel VDAC. Nature 399: 483-487, 1999.

5. Oltvai ZN, Milliman CL and Korsmeyer J: Bcl-2 heterodimerizes in vivo with a conserved homolog, Bax, that accelerates programmed cell death. Cell 74: 609-619, 1993.

6. Coll JL, Neogoescu A, Louis N, et al: Antitumor Activity of Bax and 553 naked gene transfer in lung cancer: In vitro and in vivo analysis. Hum Gene Ther 9: 2063-2074, 1998.

7. Li X, Marani M, Yu J, et al: Adenovirus-mediated Bax overexpression for the induction of therapeutic apoptosis in prostate cancer. Cancer Res 61: 186-191, 2001.

8. Tumemitu Y, Kagawa S, Tokunaga N, et al: Molecular therapy for peritoneal dissemination of xenotransplanted human MKN-45 gastric cancer cells with adenovirus mediated Bax gene transfer. Gut 53: 554-560, 2004.

9. Okumura K, Nakase M, Nakamura S, Inui M, Hiramoto K and Tagawa T: Antitumor activity of cationic liposome-mediated Bax gene transfer in osteosarcoma cells: induction of apoptosis and caspase-independent cell death. Int J Oncol 27: 433-438, 2005.

10. Marshall E: Gene therapy death prompts review of adenovirus vector. Science 286: 2244-2245, 1999.

11. Boyce N: Trial halted after gene shows up in semen. Nature 414: 677, 2001

12. Check E: A tragic setback. Nature 420: 116-118, 2002.

13. Thomas $M$ and Klibanov AM: Non-viral gene therapy: polycation-mediated DNA delivery. Appl Microbiol Biotechnol 62: 27-34, 2003.

14. Hamaguchi Y: Establishment of human osteosarcoma cell line from mandible and its sensitivity of Rhodamine 123. Mie Igaku 33: 109-120, 1989.

15. Nakase M, Inui M, Okumura $\mathrm{K}$, et al: p53 gene therapy of human osteosarcoma using a transferring-modified cationic liposome. Mol Cancer Ther 4: 625-631, 2005.

16. Kong XT, Gao H and Stanbridge EJ: Mechanisms of differential activation of target gene promoter by p53 hinge domain mutants with impaired apoptotic function. J Biol Chem 276: 32990-33000, 2001.

17. Lowe SL, Rubinchik S, Honda T, McDonnell TJ, Dong JY and Norris JS: Prostate-specific expression of Bax delivered by an adenoviral vector induces apoptosis in $\mathrm{LNCaP}$ prostate cancer cells. Gene Ther 8: 1363-1371, 2001.

18. Pirocanac EC, Nassirpour R, Yang M, et al: Bax-induction gene therapy of pancreatic cancer. J Surg Res 106: 346-351, 2002.

19. Kaliberov SA, Buchsbaum DJ, Gillespie GY, et al: Adenovirusmediated transfer of Bax driven by the vascular endothelial growth factor promoter induces apoptosis in lung cancer cells. Mol Ther 6: 190-198, 2002.
20. Groeger AM, Esposito V, Cassandro R, et al: A model of Bax gene delivery to human lung cancer. Anticancer Res 21: 3627-3630, 2001

21. Almofti MR, Harashima H, Shinohara Y, Almofti A, Baba Y and Kiwada $\mathrm{H}$ : Cationic liposome-mediated gene delivery: Biophysical study and mechanism of internalization. Arch Biochem Biophys 410: 246-253, 2003.

22. Cheng PW: Receptor ligand-facilitated gene transfer: enhancement of liposome-mediated gene transfer and expression by transferrin. Hum Gene Ther 7: 275-282, 1996.

23. Yanagihara K and Cheng PW: Lectin enhancement of the lipofection efficiency in human lung carcinama cells. Biochim Biophys Acta 1472: 25-33, 1999.

24. Arafat WO, Gómez-Navarro J, Xiang J, et al: An adenovirus encoding pro-apoptotic Bax induces apoptosis and enhances the radiation effect in human ovarian cancer. Mol Ther 1: 545-554, 2000.

25. Arafat WO, Buchsbaum DJ, Gómez-Navarro J, et al: An adenovirus encoding pro-apoptotic Bax synergistically radiosensitizes malignant glioma. Int J Radiat Oncol Biol Phys 55: 1037-1050, 2003.

26. Yanagihara K, Cheng $\mathrm{H}$ and Cheng PW: Effects of epidermal growth factor, transferrin, and insulin on lipofection efficiency in human lung carcinoma cells. Cancer Gene Ther 7: 59-65, 2000.

27. Wagener C, Bargou RC, Daniel PT, et al: Induction of the death-promoting gene Bax- $\alpha$ sensitizes cultured breast-cancer cells to drug-induced apoptosis. Int J Cancer 67: 138-141, 1996.

28. Guo B, Yin M, Tóth K, Cao S, Azrak RG and Rustum YM: Dimerization of mitochondrial Bax is associated with increased drug response in Bax- transfected A253 cells. Oncol Res 11: 91-99, 1999

29. Yanqiu Z, Bing X, Baofun C, Taidong Q and Daiming F: Upregulation of drug sensitivity of multidrug-resistant SGC7901/ VCR human gastric cancer cells by Bax gene transduction. Chin Med J 113: 977-980, 2000.

30. Kobayashi T, Sawa H, Morikawa J, Zhang W and Shiku H: Bax induction activates apoptotic cascade via mitochondrial cytochrome c release and Bax overexpression enhances apoptosis induced by chemotherapeutic agents in DLD-1 colon cancer cells. Jpn J Cancer Res 91: 1264-1268, 2000.

31. Sakakura C, Sweeney EA, Shirahama T, et al: Overexpression of Bax sensitizes human breast cancer MCF-7 cells to radiationinduced apoptosis. Int J Cancer 67: 101-105, 1996. 